\title{
Mousquetaires!, sous la direction de Matthieu LETOURNEUX et Isabelle SAFA
}

\section{Lise Sabourin}

\section{(2) OpenEdition}

\section{Journals}

\section{Édition électronique}

URL : http://journals.openedition.org/studifrancesi/15578

DOI : $10.4000 /$ studifrancesi. 15578

ISSN : 2427-5856

\section{Éditeur}

Rosenberg \& Sellier

\section{Édition imprimée}

Date de publication : 1 décembre 2018

Pagination : 508-509

ISSN : 0039-2944

\section{Référence électronique}

Lise Sabourin, "Mousquetaires!, sous la direction de Matthieu Letourneux et Isabelle safa », Studi Francesi [En ligne], 186 (LXII | III) | 2018, mis en ligne le 01 janvier 2019, consulté le 06 janvier 2021. URL : http://journals.openedition.org/studifrancesi/15578; DOI : https://doi.org/10.4000/ studifrancesi. 15578

Ce document a été généré automatiquement le 6 janvier 2021.

\section{(c) (i) (9)}

Studi Francesi è distribuita con Licenza Creative Commons Attribuzione - Non commerciale - Non opere derivate 4.0 Internazionale. 


\title{
Mousquetaires!, sous la direction de Matthieu LETOURNEUX et Isabelle SAFA
}

\author{
Lise Sabourin
}

\section{RÉFÉRENCE}

Mousquetaires!, sous la direction de Matthieu LETOURnEUX et Isabelle SAFA, Paris, Classiques Garnier, 2016, «Cahiers Alexandre Dumas» 43, 176 pp.

1 Ce quarante-troisième numéro des «Cahiers Alexandre Dumas» fournit, outre la bibliographie 2016-2017, une série d'articles liés à l'exposition conçue par Olivier Renaudeau au musée des armées des Invalides en 2014 sur la figure du mousquetaire. Comme l'expliquent Matthieu LETOURnEUX et Isabelle SAFA, dans leur introduction (pp. 11-27), ce personnage a été largement surévalué par la littérature par rapport à la place réelle qu'il a tenue dans l'histoire guerrière de la France. Le corps d'élite des mousquetaires, fondé par Louis XIII en 1622, essentiellement pour constituer le bras armé du souverain face aux protestants, connut certes un fort ascendant sur la noblesse d'épée qui y reconnut son idéal d'une aristocratie du sang versé, une possibilité d'avancement rapide de carrière par la prouesse de combats périlleux et violents. Mais, suscitant la méfiance de Mazarin, il fut dissous en 1646, avant d'être restauré en 1660 par le jeune Louis XIV qui en fit un instrument de maintien de l'ordre et une assistance à l'exécution de sa justice, sans pour autant perpétuer le lien personnel et direct qu'avait son père avec ces compagnies de gentilshommes dévoués. Sous Louis XV, ce n'était plus qu'un corps de réserve, plus enclin à la routine ou aux ambitions courtisanes qu'à des exploits guerriers devenus rares, si bien que supprimé par souci d'économies en 1775 , il ne fut que brièvement rétabli à la première Restauration de Louis XVIII, licencié aux Cent Jours, et disparut définitivement en septembre 1815.

2 Aussi doit-on vraiment à Dumas le statut extraordinaire de célébrité et de représentation de l'esprit français qui est attaché à la figure du mousquetaire. S'inspirant peut-être de la première réapparition $\mathrm{au} \mathrm{XIX}^{\mathrm{e}}$ siècle de son futur héros dans 
une nouvelle rustiquement illustrée du «Journal des enfants» en 1836, D'Artagnan ou le Jeune Duelliste, que présente Claude schopp (pp.159-166), Dumas se plonge dans les Mémoires apocryphes de d'Artagnan, rédigés en 1700 par Courtils de Sandras, et en tire la fameuse trilogie parue en 1844, 1845 et 1847, Les Trois Mousquetaires, Vingt Ans après et Le Vicomte de Bragelonne. Ces romans historiques, mais aussi d'aventures, de cape et d'épée, d'éducation, fixent l'image nostalgique des valeurs françaises de fraternité, de légèreté, de bravoure, d'esprit frondeur et de générosité. Dumas se plait à conférer à cette figure emblématique d'Ancien Régime une modestie démocratique liée à ses origines de petit gentilhomme gascon. Le mousquetaire déploie une panoplie générique de costume (rapière, chapeau à plume) et de comportement (amour du bon vin, des jurons, des cavalcades, mais aussi panache, galanterie et délicatesse) qui crée ainsi, au temps du roman-feuilleton, un type d'aventurier qui mêle au fil de l'épée dévouement patriotique au combat et morale individualiste de duelliste, un alliage plein de paradoxes, comparable au cow boy des westerns, qui explique la prolifération de ses avatars littéraires et cinématographiques dans nos sociétés mondialisées.

3 Les créateurs ultérieurs s'en sont d'autant plus facilement emparés que Dumas a laissé des béances dans la biographie de ses personnages tout en fixant leur fin, non seulement en plaçant les suites des Trois Mousquetaires «vingt ans» et «dix ans» plus tard, mais aussi en adaptant fidèlement, tout en le concentrant, son roman pour le théâtre, dans "La Jeunesse des Mousquetaires" ou "Cinq ans après» qu'étudie Julie ANSELMINI (pp.39-55). Il en a fait également le champion combatif du journalisme en casaque (Alexandre Dumas, le mousquetaire de la petite presse du Second Empire de Sarah MOMBERT, pp.57-69). Il a ainsi encouragé l'imaginaire à combler les manques autour de ces figures, en fait aussi représentatives du XIX ${ }^{\mathrm{e}}$ siècle que le gamin de Paris ou la lorette, incitant à les transposer comme il l'avait lui-même pratiqué en utilisant le XVII ${ }^{\mathrm{e}}$ siècle. C'est ce que montre Brigitte KRULIC, en expliquant combien le Mousquetaire, figure exemplaire de l'imaginaire national (pp.29-38), relève d'un romanesque historique assurant à la fois la survivance de logique aristocratique de l'honneur et les principes populaires d'après la Révolution française.

4 Les autres articles se penchent sur les auteurs qui se sont inspirés des mousquetaires, tel Paul Mahalin, continuateur de Dumas, comme l'analyse Thomas ConRAD, avec Du fils d'Athos au fils de Porthos (pp. 71-80) dans la lignée du Vicomte de Bragelonne. Jacqueline RAZGONNIKOFF voit en Cyrano de Bergerac, un d'Artagnan disgrâcié, par lequel Edmond Rostand remonte aux sources de Dumas et de quelques autres (pp. 81-93) pour transporter le personnage grâce à un sentiment de fierté nationale malgré son conflit intérieur. Lise DUMASY va, elle, de D'Artagnan à Pardaillan (Métamorphose du héros de cape et d'épée, pp. 95-112): Michel Zévaco hérite certes de Dumas, mais relègue l'histoire en toile de fond au bénéfice d'une réutilisation épique et allégorique de sensibilité anarchiste. Angels SANTA retrouve l'univers des mousquetaires dans D'Artagnan contre "Cyrano de Bergerac" de Paul Féval fils (pp.113-125), qui laisse la première place aux événements historiques. Isabelle SAFA établit le parallèle entre Hussard et Mousquetaire (Le "D'Artagnan amoureux" de Nimier, pp.127-140) qui fait preuve d'un nationalisme sentimental. Gérard GENGEMBRE voit dans Furioso et Fracasso (pp.141-145) une transposition des Mousquetaires au service de la France libre où Voldemar Lestienne dénonce la monstruosité nazie par un jeu de miroir grotesque. Enfin, François LAGRANGE décèle un dialogue implicite dans les références intertextuelles d'Arturo Perez-Reverte avec son capitaine Alatriste, un anti-d'Artagnan? (pp. 147-157). 